\title{
RENTA Y RENDIMIENTO: TIPOS DE INVERSIÓN ECONÓMICA EN EL REINO DE NÁPOLES
}

por

\author{
Mireille PeYTavin \\ Université de Toulouse II Le Mirail
}

RESUMEN: En una nota de síntesis historiográfica, la autora propone una cronología de las tendencias que rigieron la inversión de capital en el Reino de Nápoles durante el periodo del dominio español. En la primera mitad del XVI (Giulio Fenicia), vemos un desplazamiento del comercio internacional de orígenes napolitanos y con vías mediterráneas hacia un comercio basado exclusivamente en las necesidades de los reinos hispanos. Durante la segunda mitad del siglo XVI (Roberto Mantelli), vemos una inversión masiva de capital napolitano al servicio del estado, en manos de los genoveses, por un lado, y de la gran nobleza titulada, por otro. Durante la primera mitad del siglo XVII (Rosario Villari), se produce un proceso de refeudalización del campo que puede aplicarse a procesos semejantes vividos en otros territorios de la monarquía hispana. Durante la segunda mitad del siglo XVII (Michèle Benaiteau), en especial a partir de la peste de 1656 con importantes consecuencias demográficas, se produce una disminución de las tensiones entre los nobles y sus vasallos. Dinámica que supondrá durante la centuria siguiente una pacífica transición hacia una "economía comercial» que viene a sustituir la anterior "economía moral» en cuanto a las pautas seguidas para la explotación de la tierra. El reinado de Felipe II aparece, dentro de este esquema, como el momento clave en cuanto a la elección de la estrategia de inversión económica. Atribuir estos cambios a un simple aislamiento ideológico y cultural provocado por la imposición del poder monárquico español sería una simplificación. Por ejemplo, la exportación de trigo de Sicilia y de la Apulia, que tuvo su apogeo a comienzos del siglo XVI, disminuyó en los años siguientes debido al crecimiento de la población local (Maurice Aymard). Sin embargo, es indiscutible que la incorporación del reino de Nápoles en el seno la monarquía española favoreció a largo plazo la inversión en rentas del estado y los ingresos del sistema feudal. Característica que debe tenerse en cuenta para analizar una organización social que era el resultado de un compromiso inestable y continuamente negociado entre la monarquía, la nobleza urbana, la nobleza rural y sus vasallos. 
En este contexto no se debe menospreciar el protagonismo asumido por los oficiales públicos para el buen funcionamiento de dicho compromiso.

PALABRAS ClAVE: Nápoles. Monarquía española. Génova. Inversión en rentas. Renta feudal. Refeudalización. Comercio internacional.

ABSTRACT: The author provides a bistoriographic synthesis to propose a chronology of choices of capital investments in Naples during the period of Spanish dominion. During the first balf of the sixteenth century (Giulio Fenicia), a diminution of international Mediterranean commerce originating in Naples takes place, giving way to commerce focused exclusively on the needs of Spanish realms. During the second half of the sixteenth century (Roberto Mantelli), a massive investment of Neopolitan capital in the state's rents comes into play, an investment assured primarily by Genoes and titled nobility. In the first balf of the seventeenth century (Rosario Villari), a refeudalization of the rural areas takes place, building from first steps under the administration of the crown of Naples, and gaining renewed impetus from other administrative corners of the Spanish crown. During the second balf of the seventeenth century (Michele Benaiteau), there is a decrease in tensions between the seigneurs and their vassals, most particularly after the population reduction in the wake of the plague of 1656; in the following century, a peaceful transition from a "moral economy» to a "commercial economy» takes place in the exploitation of lands. Following this periodization, it is the reign of Philip II that emerges as the point where economic investment becomes the dominant factor. To attribute this to ideological and cultural rigidity stemming from the Spanish monarchy's dominance seems an over-simplification. To give just one example, the export of wheat from Sicily and Pouilles, which thrived in the beginning of the sixteenth century, decreased thereafter due to the sizeable increase in population (Maurice Aymard). Nonetheless, it is clear that the crown of Naples, once integrated into the Spanish monarchy, favored the state's rents and the reinvigoration of feudal systems. This conception should always be contemplated from the vantage point of a social structure that resulted from a constant and instable process of negotiation between the monarchy, urban nobility, rural seigneurs and their vassals. In bringing about and maintaining this compromise, office holders too bad a crucial part to play.

KEY WORDS: Naples. Spanish Monarchy. Genoa. Economic investment in rents. Feudal rent. Refeudalization.

La historiografía napolitana no ha dado aún por zanjada la cuestión de la «traición de la burguesía»; actualmente tiene tendencia a desplazar la cronología de dicho «acontecimiento» hacia comienzos del siglo XVI para ligarlo estrechamente con la instalación en la península de la monarquía española. Giulio Fenicia habla para la primera mitad del siglo XVI de una desubicación del comercio internacional de origen napolitano de los circuitos mediterráneos y de 
una concentración exclusiva sobre las necesidades de los reinos hispánicos ${ }^{1}$. Roberto Mantelli ha demostrado la existencia, durante la segunda mitad del siglo XVI, de una inversión masiva de los capitales disponibles en el reino de Nápoles en rentas del estado; inversión efectuada fundamentalmente por los genoveses y por la nobleza titulada ${ }^{2}$. Rosario Villari ha constatado y descrito, para la primera mitad del siglo XVII, un proceso de "refeudalización» ${ }^{3}$ que, desde su modelización para el caso del reino de Nápoles, ha sido aplicado asimismo para explicar lo sucedido en otros territorios de la monarquía española Michèle Benaiteau sugiere, por último, que durante la segunda mitad del siglo XVII, en particular con motivo de la peste de 1656 y favorecido por la tendencia demográfica, se produciría un apaciguamiento de las terribles tensiones existentes entre señores y campesinos y la sustitución, más pacífica a lo largo de la centuria siguiente, de una «economía moral» por una «economía mercantil» en la explotación de las tierras5.

El periodo correspondiente al reinado de Felipe II se caracterizaría, según este esquema, por una vuelta atrás a la hora de efectuar la inversión económica. Atribuir este cambio a un aislamiento ideológico y cultural del reino provocado por su entrada en el seno de la monarquía española constituye, sin embargo, una visión histórica singularmente mezquina. Basta citar un ejemplo: la exportación de trigo de Sicilia y la Apulia hacia el resto de los países mediterráneos, tan floreciente a comienzos del siglo XVI, sufre una marcada disminución motivada por el impresionante crecimiento de la población local, que se dobla en un siglo, y cuya demanda resulta evidentemente prioritaria con relación al comercio nternacional ${ }^{6}$. Ahora bien, parece innnegable que la inversión económica en el reino de Nápoles, al igual que en el resto de las posesiones españolas, privilegió de un modo constante tanto la renta del estado como la renta feudal. Constatación que debe situarse en el marco de una organización social que era el resultado de un compromiso inestable entre la monarquía, la nobleza urbana, el señorío rural y los vasallos; compromiso en el que se veían igualmente involucrados los oficiales públicos.

1 Fenicia, Giulio: Politica economica e realtà mercantile nel regno di Napoli nella prima metà del XVI secolo (1503-1556), Bari, 1996.

2 MANTELLI, Roberto: L'alienazione della rendita pubblica e i suoi acquierenti dal 1556 al 1583 nel regno di Napoli, Cacucci, Bari, 1997.

3 VILLARI, Rosario: La rivolta antispagnola a Napoli. Le origini (1585-1647), Bari, 1987 (1967).

4 YUn CaSAlilla, Bartolomé: «La aristocracia castellana en el seiscientos. ¿Crisis, refeudalización u ofensiva política?»: Revista Internacional de Sociología 45 (1987) 77-104; ATIENZA HeRNÁNDEZ, Ignacio, «Refeudalización en Castilla durante el siglo XVII : ¿Un tópico?»: Anuario de Historia del Derecho Español (1986) 889-920.

5 BENAITEAU, Michèle: Vassalli e cittadini. La signoria rurale nel Regno di Napoli attraverso lo studio dei feudi dei Tocco di Montemiletto (XI-XVIII secolo), Bari, 1997.

6 AYMARD, Maurice: contribución al $5^{\circ}$ Coloquio de Flaran, L'approvisionnement des villes de lEurope occidentale au Moyen âge et aux Temps Modernes, Auch, 1985.

Hispania, LXI/2, núm. 208 (2001) 521-538 


\section{TIPOS DE INVERSIÓN ECONÓMICA: EL COMERCIO INTERNACIONAL}

Un primer tipo de inversión económica en el reino de Nápoles es aquél relacionado con la actividad comercial internacional. Los productos comercializados son el trigo, el aceite, el vino, la sal, el hierro, la seda, el ganado, así como ciertas especies: azafrán, anís, comino, almendras ${ }^{7}$. La función de granero de trigo y de proveedora de aceite y vino ejercida por la región de la Apulia era bien conocida en la cuenca mediterránea. Las provincias adriáticas del reino de Nápoles tuvieron, de este modo, la posibilidad, largamente aprovechada durante el siglo XV bajo las dinastías angevina y aragonesa, de participar en el abastecimiento de la república de Venecia. Estas regiones suministraban asimismo especias. El hierro y sobre todo la seda eran más bien una especialidad de las dos provincias calabresas que exportaban principalmente sus productos hacia Florencia, Génova y Valencia.

Para medir la importancia del comercio internacional realizado desde el reino de Nápoles, Giulio Fenicia se ha visto obligado a recurrir a sinfín de fuentes diferentes, todas ellas fragmentarias y de difícil relación. Con altas dosis de paciencia y de ingenio, ha conseguido alcanzar resultados que ofrecen material para la discusión. Fuentes que, sin embargo, deben permanecer sometidas a una estricta crítica conducida con rigor y severidad con objeto de dotarlas del necesario grado de fiabilidad. G. Fenicia ha tenido en cuenta, en primer lugar, la reglamentación destinada a autorizar o prohibir las exportaciones de los diferentes productos disponibles. Los reglamentos y las pragmáticas tendrían como principal fuente de origen el círculo del virrey y del Consejo Colateral, aunque no debemos olvidar que los monarcas españoles siguieron con atención estos asuntos. No obstante, los documentos más precisos, ya que nos permiten obtener evaluaciones cuantitativas a la vez que ofrecen información sobre las mercancías y los precios, son los contratos nominativos llamados tratas, permisos escritos de los virreyes para la exportación de cantidades determinadas de vino o de trigo.

Las tratas sirven, que duda cabe, como un indicador comercial para los inversores; representan igualmente un soporte fiscal de singular importancia. En primer lugar, son vendidas legal o ilegalmente, lo que produce un ingreso neto. A continuación, vienen tasadas. En efecto, el virrey y los regentes del Colateral fijan el precio del trigo en el reino, poniendo límites a los contratos «alla voce", compromisos anteriores a la cosecha, establecidos entre campesinos y comerciantes. Fijan igualmente los precios, mucho más elevados, para aquellas partidas destinadas a la exportación: en los años buenos, la diferencia proporciona un ingreso nada despreciable para la administración del reino. Por último, las tratas también pueden servir de garantía para determinados préstamos. En este caso son el objeto de "partidos», cuando no son utilizadas directamente para su reembolso. No hay comercio sin fiscalidad; es justamente lo que nos

\footnotetext{
7 Fenicia, Cap. 1.
}

Hispania, LXI/2, núm. 208 (2001) 521-538 
permite medirlo. Pero asimismo no existe fiscalidad sin sistemas de control, y por consiguiente sin fraude; lo que nos fuerza a ser bastante críticos con respecto a este tipo de fuentes.

Giulio Fenicia establece también gráficos y tablas a partir del montante del arrendamiento de las aduanas de Nápoles, la Apulia y Calabria, que, cabe suponer, se negociaba en función del rendimiento que se esperaba sacar de ellas. De nuevo, los ingresos fiscales sirven para medir la intensidad del comercio y la fiscalidad aparece como múltiple, escalonada. Ante todo, las aduanas constituyen simplemente un primer grado de tasación directa sobre las mercancías para mayor provecho de la monarquía. A continuación, representan el soporte para añadir, por parte del arrendatario, un gravamen suplementario que constituye su beneficio. Las aduanas son utilizadas igualmente como fundamento de los préstamos solicitados por la monarquía, como garantía para los hombres de negocio. Por último, y como hemos observados en el caso de las tratas, podían servir eventualmente como reembolso directo de los préstamos, por medio de títulos de deuda situados sobre las aduanas.

Es preciso señalar que el arrendatario principal raramente actuaba solo. Lo normal era que recurriese a dividir el arriendo entre múltiples sub-arrendatarios que velaban directamente sobre sus intereses particulares. En suma, y dentro de una lógica mercantil, es de suponer que el montante del arriendo tendiese a evaluarse a la baja: es precisamente en este intersticio de beneficio donde reside el atractivo derivado de este tipo de contrato. La manipulación de las cifras de los arrendamientos aparece pues particularmente delicada. ¿Es posible deducir de ellas una tendencia general? Tan sólo si tenemos en cuenta como factor de corrección la existencia determinadas habilidades individuales, de coyunturas minúsculas. Ante todo debe quedarnos claro que las aduanas no nos permiten observar la totalidad de las transacciones comerciales. Como subraya con acierto el autor, es imposible medir el contrabando, en particular el que se practicaba a lo largo de la frontera terrestre con los Estados Pontificios ${ }^{8}$.

G. Fenicia ha intentado completar este conjunto de informaciones, obtenido de hecho a partir de fuentes muy sesgadas, mediante la búsqueda de documentos que acrediten la presencia de barcos napolitanos en diversos puertos mediterráneos como Venecia, Ragusa, Valencia y Génova. Gracias a la investigación llevada a cabo en distintos archivos situados en puertos del Mediterráneo, ha obtenido preciosas indicaciones sobre la existencia de una importante corriente de importación de ciertos productos como el cuero y las pieles, proce-

\footnotetext{
8 Algunos ejemplos de fraude en PEYTAVIn, Mireille, «Aduanas locales y privilegios de ciudadanía: tentativas de intervención institucional de la monarquía española en las provincias del reino de Nápoles», Pereira Iglesias, José Luis; González Beltrán, Jesús Manuel (eds.) Felipe ll y su tiempo, Actas de la V Reunión Científica, Asociación Esoañola de Historia Moderna, Cádiz, 1999, vol. I, pp.329-334; YuN CASAliLla, Bartolomé: «Corrupción, fraude, eficacia hacendística y economía en la España del siglo XVII": Hacienda Pública española. El fraude fiscal en la bistoria de España 1 (1994) 47-60.
} 
dentes de Europa oriental vía Ragusa. Estudia, por último, el peso de las jurisdicciones particulares que organizaban la fiscalidad mediante gravámenes sobre las transacciones comerciales en los puertos, las ferias y los mercados.

La yuxtaposición de estos diferentes elementos, y de otros que no hemos citado aquí, permite alcanzar una impresión de conjunto y enmarcar la evolución del comercio internacional efectuado desde el reino de Nápoles en un cuadro cronológico preciso. El autor llega a la conclusión de que se podría hablar de un desapego de los mercaderes napolitanos, o de aquellos que operaban a partir del reino de Nápoles (la precisión es importante), con respecto a las transacciones internacionales. Desinterés que sería prácticamente total a partir de mediados del siglo XVI y que contrastaría con la precedente buena integración en los circuitos de intercambio mediterráneos de, al menos, una parte importante de determinadas regiones napolitanas, como la Apulia, la Calabria o la Tierra de Otranto.

Desinterés que procede de un buen número de causas. La producción de las provincias adriáticas, trigo, aceite y vino, abandona sus mercados naturales, esto es Venecia y Ragusa, para dirigirse exclusivamente hacia el aprovisionamiento de la capital, cuyo monstruoso crecimiento constituye un problema constante de preocupación para sus gobernantes. El peso creciente de la fiscalidad a lo largo de la primera parte del siglo XVI provoca una marcada disminución de los beneficios. La rigidez del marco reglamentario constituye, a su vez, un factor más de desaliento para los mercaderes. Los elevados precios del cereal napolitano lo convierten en poco competitivo. Además, pocos capitales de origen napolitano se invierten en el comercio napolitano. La integración en un conjunto más vasto como lo era el de la monarquía española significó, por lo tanto, para el reino de Nápoles, un repliegue hacia un proteccionismo estático, agravado por la prohibición de exportar oro y plata, y que estrangulaba cualquier veleidad de operar en los circuitos internacionales por la primacía concedida al abastecimiento interno.

En términos de inversión económica, los datos no nos resultan totalmente esclarecedores y las conclusiones alcanzadas aparecen como más que dudosas. La integración de los mercaderes de origen napolitano en los circuitos mediterráneos de intercambio está mal documentada : por nuestra parte no seríamos capaces de extraer conclusiones ni sobre su posible presencia ni sobre su ausencia. Por el contrario, la actividad de los genoveses ha sido señalada y estudiada desde hace tiempo. Ahora bien, el pretendido distanciamiento del reino de Nápoles hacia el comercio internacional no significó en ningún caso la desvinculación de los genoveses ni su abandono de tales actividades. Podemos observar en su numerosa presencia el mejor testigo del mantenimiento de una importante actividad mercantil. Las galeras que ordenan construir en el Arsenal de Nápoles no van destinadas tan sólo a servir de modo ocasional a la monarquía para el fortalecimiento de su escuadra.

La monarquía española impone el sistema de las tratas, al menos para el trigo, con el fin de asegurar el abastecimiento de la población residente en los

Hispania, LXI/2, núm. 208 (2001) \$21-538 
reinos de Nápoles y Sicilia ¿Representó esta medida un freno total para su exportación? Sí, sin duda, en términos cuantitativos, al existir un drástico control de las cantidades por los virreyes; no en términos de obstrucción financiera, pues los consumidores más habituales, Sicilia, Florencia, Venecia, y los Estados pontificios, estaban exentos del pago de tasas. Además, la producción de seda calabresa, cuya exportación no estaba regulada, se hunde a lo largo del siglo XVII ante los embates de la concurrencia siciliana 9 .

¿Por qué protegerse de un modo tan obsesivo de toda posible penuria de cereales? Giulio Fenicia ofrece algunas cifras, hipotéticas, que nos permiten tener una idea sobre los rendimientos del trigo en el siglo XVII ${ }^{10}$ : en las planicies del norte de Italia, la relación entre recogida y siembra oscilaría entre 5 por 1 y 2-3 por 1 en los lugares más cercanos a las colinas. Alrededor de Roma, se obtendría 8 por 1 para alcanzar hasta 12 por 1 en Sicilia. La media en el reino de Nápoles estaría aproximadamente en torno al 4 por 1 con cifras de 6 por 1 en la Apulia o en la Calabria. Las comparaciones son reveladoras, sobre todo si tenemos en cuenta que la productividad permanece rigurosamente invariable a lo largo de toda la Edad Moderna debido a la ausencia de avances técnicos necesarios para incrementar los beneficios. Los únicos factores capaces de provocar un aumento de la producción reposan en ampliar la superficie cultivable o en incrementar el número de hombres, sin olvidar claro está las cambiantes condiciones climáticas. En el contexto de un aumento demográfico tan sostenido como el acaecido a lo largo del siglo XVI, que permitió doblar el número de la población de Sicilia y del reino de Nápoles, el mantenimiento de un comercio internacional sin modificaciones hubiera conducido irremediablemente a un periodo de hambrunas.

Por el contrario, las necesidades de transacción y transporte se mantuvieron estables. Es por lo tanto legítimo pensar que las estructuras comerciales continuaron a ser utilizadas y demandadas al mismo ritmo que antes. Los cereales conducidos de la Apulia hacia Nápoles lo eran por vía marítima, mucho más rápida y barata que la vía terrestre. Organización que requería de un número de inversiones comparable a las del comercio internacional, así como barcos, tripulación, seguros, intermediarios en los puertos, desubicación de los pagos mediante letras de cambio y medidas de protección contra los ataques berberiscos. Además esta "nacionalización» del comercio de los productos alimenticios debe quedar matizada por una definición igual de cuidadosa de su precedente «internacionalización». G.Fenicia recuerda con acierto la toma de posesión por parte de los venecianos de las costas de la Apulia entre 1528 y 1529 , en concreto de centros como Barletta, Molfetta, Trani, Monopoli y Polignano, todos ellos importantes puertos de embarque de productos alimenticios. Del mismo modo, Bona Sforza, reina de Polonia, gestiona directamente su señorío, la ciudad de Bari y su territorio, hasta su muerte en 1557.

\footnotetext{
9 GALASSO, Giuseppe: Economia e società nella Calabria del Cinquecento, Nápoles, 1992 (1967).

10 Fenicia, 32.
} 
Por último, el comercio local y el de cabotaje representan una dimensión absolutamente esencial de las estructuras comerciales y deben ser considerados con atención pues son sectores productores de grandes cantidades de riqueza, aunque sea difícil medir la totalidad de su montante. Tan sólo la abigarrada red aduanera y de depósitos nos permite comprender la importancia de los intercambios locales y regionales con motivo de las ferias y los mercados. En conclusión, la vitalidad del comercio «internacional» se dirigió directamente hacia el sector «nacional», en el marco de las rígidas reglamentaciones de la monarquía. Las estructuras, las fuentes y las cantidades de la inversión económica comercial no sufrieron más que ligeras adaptaciones y es imposible calcular la evolución de los beneficios derivada de dicha modificación. En lo referente a las débiles transacciones internacionales subsistentes, la inserción del reino de Nápoles en la monarquía española condujo, en efecto, a un abandono del socio comercial veneciano como destinatario de cereales que sería reemplazado por Valencia y Andalucía. El resto de los intercambios, por ejemplo con Ragusa, parece haberse mantenido.

\section{TIPOS DE INVERSIÓN ECONÓMICA: LAS RENTAS DEL ESTADO}

Un segundo tipo de inversión económica en el reino de Nápoles aparece en la segunda mitad del siglo XVI, como en el resto de los territorios de la monarquía española y de las otras monarquías europeas. La Cámara de Cuentas sería la encargada de determinar, cada cierto tiempo, cuáles eran las porciones del patrimonio real, el fisco, que se podrían enajenar con objeto de proporcionar dinero. El abanico de posibilidades era bastante variado: la monarquía podía enajenar feudos, comunidades de realengo, jurisdicciones, oficios, derechos, la recaudación de los impuestos directos (el donativo pagado por fuego o focatico) o indirectos (las gabelas). Los contratos de venta incluían normalmente un pacto de restitución (retrovendita) lo que permitía a la monarquía echar marcha atrás cuando lo creyese oportuno a cambio del reembolso de la suma pagada al comienzo.

La Cámara de Cuentas ofrecía asimismo el arrendamiento de la recaudación de los impuestos, o del ejercicio de las jurisdicciones, o de la construcción y mantenimiento de las galeras, o de cualquier operación llevada a cabo por la monarquía. En paralelo con el proceso de arrendamiento, la Cámara de Cuentas podía decidir que el producto de cualquiera de los impuestos se colocase para cubrir el pago de los intereses adeudados a sus acreedores. En este caso, el arrendatario remitía directamente a los acreedores la parte de las ganancias del impuesto que les correspondía. Finalmente, los arrendatarios, por propia iniciativa, podían lanzar operaciones parecidas cuando ellos tuviesen necesidad de liquidez. Concretamente, ¿cuáles eran las posibilidades de inversión ofrecidas a los napolitanos que deseaban colocar sus excedentes financieros? Podían comprar ya fuese fiscali, que correspondían a los impuestos directos, ya fuese arren- 
damenti, que correspondían a los impuestos indirectos. Los podían comprar tanto en la Cámara de Cuentas, como a un grupo de hombres de negocio que a su vez los habían comprado a la Cámara de Cuentas, o incluso a los arrendatarios. Fiscali y arrendamenti se vendían con una tasa de interés garantizado. Este desmenuzamiento de la oferta financiera la hacía accesible a prácticamente todos los niveles de riqueza: del especulador, que solía realizar adquisiciones masivas antes de fraccionarlas y revenderlas, al pequeño ahorrador que adaptaba sus inversiones a las posibilidades del momento.

Este segundo tipo de inversión económica correspondía pues a la compra de títulos de deuda garantizados por el estado, esto es a aquella actividad consistente en el préstamo de dinero al Estado a cambio de unos intereses situados sobre los impuestos. Operación financiera que podía adoptar muchas modalidades, según los objetivos perseguidos y según los momentos. Los contemporáneos realizaban una nítida distinción dentro del grupo de hombres de negocio entre arrendatarios, administradores y prestamistas ${ }^{11}$ y a veces es difícil descubrir su identidad. En el reino de Nápoles, los genoveses mantuvieron una presencia masiva en este sector, al igual que en el de las transacciones comerciales. Para ello se introducían en las estructuras administrativas y compraban cargos de recaudadores provinciales con objeto de controlar directamente la recaudación de los impuestos ${ }^{12}$.

Sin embargo, los genoveses, a pesar de que el montante de sus inversiones los coloque en primer lugar, no eran los únicos poseedores de capitales que invertían en este sector. No sólo los préstamos emitidos por la monarquía quedaban siempre cubiertos sino que la compra de rentas del estado despertaba igualmente un interés irresistible entre la práctica totalidad de aquellas categorías sociales que disponían de excedentes financieros. Las rentas del estado gozaban de una buena reputación mantenida a largo plazo, incluso mejor que en Castilla. En la segunda mitad del siglo XVI, no es extraño que este tipo de inversión fuese rigurosamente el único, y que se mantuviese a lo largo de los años en conformidad con las nuevas disponibilidades monetarias de los ahorradores. Me gustaría llamar la atención sobre el grupo de oficiales napolitanos que utilizaba sus salarios para financiar al estado que les pagaba, cuando les pagaba, con una constancia y una confianza absolutamente destacables, siguiendo para ello el modelo de análisis ofrecido por Robert Descimon ${ }^{13}$.

11 BAYARD, Françoise: Le monde des financiers au XVII siècle, Paris, 1988; DeSSERT, Daniel, Argent, pouvoir et société au Grand Siècle, Paris, 1984; para el reino de Nápoles: CaLABriA, Antonio, «Finanzieri genovesi nel regno di Napoli nel Cinquecento»: Rivista Storica Italiana (1989) 578-613.

12 MUTO, Giovanni: «Una vicenda secolare : il radicamento socio-economico genovese nella Spagna de Los Austrias»: Quaderni franzoniani 2 (1996) 7-23; Id., «Una struttura periferica del governo dell'economia nel Mezzogiorno spagnolo: i Percettori provinciali»: Società e Storia 19 (1983) 1-36.

13 Descimon, Robert: «Les élites du pouvoir et le prince : l'Etat comme entreprise», París, 1996: REINHARD, Wolfgang (dir.), Les élites du pouvoir et la construction de l'Etat en Europe, págs. 133-162. 
Véase por ejemplo el caso de Alfonso Salazar, regente del Consejo Colateral $^{14}$, que declara treinta mil ducados de patrimonio ante el visitador general Lope de Guzmán entre 1581 y 1584. Salazar posee «cinco mil ducados con los que ha comprado otro tanto de renta en pagos fiscales (impuestos directos, normalmente el donativo) a Franco Ferretio sobre Ugento, Ostugni y Bagnulo... Otros once mil en tres contratos destinados también a pagos fiscales comprados a la Cámara de Cuentas sobre Barletta, Sessa, Laurino, Diano, y otros lugares. Tres mil ducados con los cuales ha comprado otro tanto de rentas a Michel Giovan Gómez. Doscientos cincuenta ducados de principal destinados a la renta de la gabela de la seda. Otros quinientos cincuenta con los que ha comprado otro tanto de rentas a Mercurio d'Aless y Aniballe Macedonio» ${ }^{15}$.

Las rentas del estado que posee Alfonso Salazar han sido adquiridas según todos los modos operatorios posibles: directamente a la Cámara de Cuentas, a través de hombres de negocio que actúan solos o asociados. Sus intereses se cobran ya sea sobre el pago de los impuestos directos de determinadas comunidades, ya sea sobre un impuesto indirecto como la gabela de la seda, o incluso le son suministrados por los hombres de negocio con los que ha efectuado las operaciones. Alfonso Salazar realiza además otros dos tipos de inversión. En primer lugar, compra un jardín en Chiaia, el barrio de moda en Nápoles, que da sobre la bahía y donde se retira a descansar. Después, Salazar paga mil doscientos y ochocientos ducados por dos cargos públicos, destinados a cada uno de sus dos hijos. El montante de los salarios de los tres oficios familiares, así como el producto de diversos beneficios eclesiásticos recogidos por uno de los hijos, se destinan a la compra de otras rentas del Estado: "he empleado todas estos ingresos en la compra de rentas según la ocasión» ${ }^{16}$.

Determinar la identidad de aquellos que invierten en rentas del estado constituye una apuesta histórica de primer orden, y ello por múltiples razones. Estos préstamos emitidos por la monarquía drenan capitales que podrían haber sido efectivamente utilizados en otros sectores, y en otras actividades con una mayor capacidad dinamizadora de la sociedad: el tema no es nuevo. Sin embargo, estos capitales son igualmente el fruto de una coyuntura demográfica y económica particularmente favorable. El rápido desarrollo del aparato administrativo a lo largo del siglo XVI favoreció la aparición de un grupo de oficiales, remunerados mediante salarios o emolumentos, y exentos del pago de impuestos. Financiar a

14 Archivo General de Simancas, Secretarías Provinciales, legajo 387, folio 16 : Discarico d'Alfonso di Salazar già Regente nel Collateral di Napoli.

is «Cinque mille ducati con li quali teneva comprata tanta rendita di pagamenti fiscali da fran.co Ferretio sopra Ugento, Hostuni, et Bagnulo... Altri undecimilia che tiene in tre partite impiegati pure in pagam.ti fiscali comprati dalla Ra Corte sopra Barletta, Sessa, Laurino, Diano, \& altri luoghi. Tre milia ducati con li quali tiene comprata tanta intrata da Michel Giovan Gomez. Ducento et cinquanta duc.ti di principale impiegati sopra la rendita della gabella della seta. Altri cinquecento cinquanta de quali comprò tanta intrata da Mercurio d'Aless. et Aniballe Macedonio».

16 «Tutte queste partite andò impiegando conforme all'occasioni in tante intrate».

Hispania, LXI/2, núm. 208 (2001) 521-538 
una monarquía, que garantiza su status social, responde a sus intereses tanto a largo como a corto plazo. Esta tendencia de los oficiales napolitanos a invertir en rentas del Estado continúa a lo largo de todo el siglo XVII ${ }^{17}$ a pesar de la paulatina caída de los beneficios: $10 \%, 9 \%, 8 \%$, hasta llegar a 7,5 o $7 \%$.

En su trabajo sobre la alienación de las rentas del reino de Nápoles entre 1556 y 1583, Roberto Mantelli utiliza un documento realizado por la Cámara de Cuentas, a petición del visitador general Lope de Guzmán, por el que se reagrupaba el montante de las ventas y los nombres de los compradores de títulos de deuda del Estado durante este periodo. Al abarcar un lapsus de tiempo relativamente corto, el resultado es esclarecedor. A partir de este documento logra identificar a los compradores de casi la mitad del valor de los títulos de renta, ya sea en capital, ya sea en rentas. Estos quedan repartidos equitativamente entre la nobleza titulada y los genoveses sin título, a los que se suma un pequeño porcentaje destinado a determinadas comunidades religiosas, obras de asistencia o comunidades (tres veces la ciudad de Nápoles, una vez una universidad). El reparto es muy estable sea cual sea la renta o el año considerados. Estos criterios de referencia merecen una explicación. Aunque ofrecen la ventaja de no inventarse categorías sociales inexistentes, a su vez limitan considerablemente las conclusiones que uno podría esperar de este tipo de fuente.

La categoría «nobleza titulada» es fácil de reconocer. Corresponde a los señores poseedores a la vez de un título y de un feudo. Invierten en la compra de rentas del Estado, los beneficios extraídos de la explotación de su señorío y del ejercicio de sus derechos feudales. De todos modos, el documento no ofrece información para aquellos casos en los que el comprador se encuentra entre otras categorías de la nobleza napolitana, esto es nobleza no titulada o barones, nobles urbanos de las piazze que ocupan un puesto en el gobierno de la ciudad o incluso nobles urbanos fuori piazze.

La categoría "genoveses» es quizá más difícil de manejar. R.Mantelli ofrece una explicación sobre sus métodos de identificación ${ }^{18}$ lo que no suele ocurrir entre aquellos autores que tratan sobre los genoveses. Incluye en esta categoría a los que poseen un nombre incluido dentro de los veintiocho alberghi que reagruparon a la elite genovesa después de la reforma de 1528 , y a aquellos cuyo nombre de familia fue suprimido por esta misma reforma (los nombres cuyo uso ha sido suprimido quedan enumerados en el documento), y de nuevo restablecido en 1576. Tratándose de ramas familiares instaladas en territorio napolitano a veces desde hace muchas generaciones, ¿es pertinente la distinción? La respuesta no puede ser sino afirmativa: los genoveses son percibidos e identificados como tales, sus intereses están representados por un cónsul de la na-

\footnotetext{
17 Peytavin, Mireille: «Patrimoines des officiers», anexo a La Visite comme moyen de gouvernement dans la monarchie espagnole. Le cas des Visites Générales du royaume de Naples XVI $-X V I I^{\ell}$ siècles, Tesis doctoral, Ecole des Hautes Etudes en Sciences Sociales, París, 1997.

18 MaNTElli 42.
} 
ción genovesa en Nápoles, se preocupan de mantener su inscripción en los libros de los alberghi, lo que hace siempre posible su vuelta a la ciudad de la que su familia es originaria. En realidad, la categoría de «genovés» va más allá del simple hecho de la nacionalidad. Se caracterizaría ante todo por una dedicación específica a asuntos comerciales y financieros, lo que nos permite aclarar, en cierta medida, el origen de los capitales invertidos en las rentas del estado.

Los compradores que no forman parte ni de la categoría de «nobleza titulada» ni de la categoría de "genoveses» constituyen un poco más de la mitad de las sumas contabilizadas en el documento. Sus inversiones suelen ser mínimas y pueden repetirse a lo largo de los años. Estas inversiones son probablemente el fruto de un ahorro de larga, incluso muy larga duración, destinado a ser conservado, dado en dote, legado en herencia, y utilizado para la compra de bienes inmuebles, de tierras. La circulación de las rentas parece, sin embargo, intensa; la oferta, permanente: proviene de los compradores masivos de las dos primeras categorías citadas, para quienes la inversión puede realizarse a muy corto plazo.

Volvamos al ejemplo de Alfonso de Salazar. Sobre un total de diecinueve mil ochocientos ducados colocados en títulos de renta y señalados en su declaración de patrimonio, el documento analizado por R.Mantelli no constata más que la presencia de ochocientos cuarenta y cuatro ducados comprados directamente a la Cámara de Cuentas (ciento ochenta ducados en 1569 al 9\%, trescientos sesenta en 1573 al $9 \%$, setenta y dos en 1575 al $9 \%$, ciento sesenta y después setenta y dos en 1577 al 8\%). Incluso teniendo en cuenta eventuales omisiones en el documento, la diferencia es bastante significativa. ¿Cómo conciliar este ahorro y los miles de ducados realmente invertidos? Asimismo, ¿ cómo situar las compras de Gio Antonio Polverino, oficial comisario de cuentas, que adquiere en 1577 sucesivamente títulos por cuarenta, doce, ocho y dieciséis ducados de rentas ${ }^{19}$ ? ¿Qué pensar de Pietro Antonio Stinca, presidente de la Cámara de Cuentas, que coloca doscientos ducados al $9 \%$ en 1569 , un poco menos de cuarenta al $9 \%$ en 1570 , veinte al $8 \%$ en 1570 , ciento ochenta al $9 \%$ en $1571^{20}$ ? ¿No se cifraban sus títulos de renta, los de todos ellos, en miles de ducados? En todo caso, los patrimonios estudiados antes ${ }^{21}$, declarados por determinados oficiales en 1611 ante otra visita general, contienen casi todos, arrendamenti, en proporción, por supuesto, bastante variable.

\section{TIPOS DE INVERSIÓN ECONÓMICA: EL FEUDO Y EL SEÑORÍO}

La «refeudalización» del siglo XVII, según el modelo establecido por Rosario Villari para el reino de Nápoles, se ha convertido en un topos historiográfi-

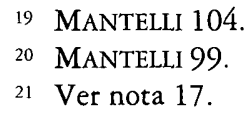


co que hace inútil una nueva exposición del mismo. La propuesta ha sido abordada por todos los historiadores del reino de Nápoles. Por ejemplo, es a partir de la discusión de la cronología utilizada por Villari, que Roberto Mantelli construye la conclusión de su obra sobre la alienación de la renta en el siglo XVI. Aunque puesto frecuentemente en duda, criticado, contestado, y a menudo desplazado en el tiempo, el modelo de refeudalización de Villari tiene el inmenso mérito de haber subrayado la centralidad de la feudalidad en todo análisis económico y político de la época moderna y, por contraste, ha servido para redimensionar, entre otros fenómenos, la cuestión del control de los órganos de gobierno por parte de los burócratas y el desarrollo paralelo de las instituciones centrales judiciales y financieras.

La atención exclusiva dedicada al feudo por parte de Villari ha convertido su modelo en excesivamente rígido. El feudatario — barón o titulado- es el depositario de los privilegios reales, de los que goza por delegación, reservándose la monarquía el dominio directo y confiándole el dominio útil. Por consiguiente, la masiva inversión en el feudo, bien constatada para el siglo XVII, es ante todo analizada en términos de exasperación de los conflictos entre señores y vasallos, de endurecimiento de las exigencias productivas, para la reserva señorial, y fiscales, para las otras tierras, de denegaciones repetidas de los derechos de los vasallos, de nuevas imposiciones forzadas o de antiguas imposiciones caídas en desuso e inopinadamente restablecidas, todo ello en un ambiente cargado de violencia.

La fuerte presión impuesta por los feudatarios a las universidades es consecuencia del aumento de su número - nobles titulados y barones se encuentran en constante progresión a medida que la monarquía vende títulos y feudos. Es consecuencia asimismo del aumento de sus necesidades materiales -la instalación masiva de los nobles en la capital durante el siglo XVI les exige un tren de vida diferente. Sin embargo, es necesario relativizar la ruptura de los años 1580-1620. Ante todo en términos de comportamiento: como demuestra pertinentemente R. Mantelli, los nobles titulados invierten sus capitales en las rentas del Estado bastante antes del siglo XVII, en realidad, desde el momento en que estas rentas salieron a la venta; se deberían relativizar igualmente los términos mismos del análisis, reintroduciendo con fuerza, como lo ha hecho Michèle Benaiteau, una separación semántica entre feudo y señorío.

M. Benaiteau reconstruye la historia de esta separación en su obra sobre «vassali e cittadini». El señorío existe al lado del feudo, incluso existe antes que el feudo. Hacer la historia del señorío consiste en reconstruir las relaciones que los hombres y las comunidades han sabido establecer y negociar entre ellos y con sus señores. Encuadrada en este marco, la exacerbación de los conflictos del siglo XVII correspondería menos a una agravación guerrera de la explotación de los hombres por los nobles, que a una nueva fase, en una historia a más largo plazo, de la negociación secular en torno a unos derechos de propiedad y de disfrute del suelo. Esta negociación, extremadamente consciente por ambas 
partes, se opera por medio de repetidas tentativas de control sobre las jurisdicciones más alejadas, lo que supone la entrada de la monarquía en estos conflictos. Desde la desaparición de la esclavitud y más tarde de la servidumbre, los vasallos napolitanos tuvieron la costumbre de ver cómo la monarquía mediaba en sus repetidos conflictos con los señores, como sucede en el caso de Carlo Tapia en el siglo XVII: la condición de hombre libre supone el derecho de apelación a la justicia real y, en contrapartida, el deber de pagar impuestos.

Es indudable que el contexto económico y político de la segunda mitad del siglo XVI y de la primera mitad del siglo XVII contribuyó a redefinir las relaciones existentes entre señores y vasallos. El auge demográfico de finales del siglo XVI - probablemente tres millones de habitantes en $1595^{22}$ - condujo a un endurecimiento de estas relaciones, en especial en el ámbito fiscal y social. Las roturaciones y el desarrollo de la ganadería se organizan por parte de los señores siguiendo sus propios criterios al tener frente a ellos a una plétora de candidatos para las tierras censales. Aunque nadie se salva de la crisis económica de los años 1620, las universidades declaraban ya desde hacía decenios encontrarse en grandes dificultades. La implacable progresión de la recaudación fiscal llevada a cabo por una monarquía acosada a su vez por la escasez de medios, se percibe por las comunidades como la causa directa de su asfixia financiera. Ahora bien, un análisis de los informes de cada una de las universidades declaradas en suspensión de pagos - verdadera huelga fiscal- por una comisión reunida desde 1628 en torno al regente Carlo Tapia (I stati discussi), permite matizar debidamente una acusación tan unívoca.

La comisión recorta de un modo sistemático los gastos de las universidades: éstas pretenden, por lo tanto, dar prioridad a un tipo de inversión más inmediata, lo que resulta en principio irreprochable de no ser porque denota los verdaderos límites de su pretendida crisis presupuestaria. Por otra parte, la huelga fiscal de las universidades puede ser completa y comportar el cese del pago de los derechos señoriales. Estos últimos están comprometidos a veces desde hace muchos años en un tipo de relaciones difíciles de definir con sus vasallos, mezcla de solidaridades, protestas, familiaridades y agresividad. Sirva como ejemplo el caso de la universidad de Montaperto, señorío de la familia Tocco $^{23}$. La universidad endeudada con su señor, cuyos intendentes extraen intereses con una tasa del $10 \%$ en lugar de la tasa legal del $7 \%$, situación que difícilmente podría pasar desapercibida. Cuando Carlo Tapia, en 1630, solicita un nuevo cálculo de los reembolsos según una tasa adecuada, la universidad demuestra haber entregado treinta ducados de más, sin que se proceda por ello a exigir su devolución al señor «con la esperanza de ser bien gobernados y protegidos en lo venidero» ${ }^{24}$. En el ámbito general del reino, las relaciones entre

22 Benaiteau 136

23 BENAITEAU 188

24 «da donde s'have speranza per l'advenire haverno da essere ben protetti et governati».

Hispania, LXI/2, núm. 208 (2001) 521-538 
señores y vasallos no se distenderán hasta después del terrible bache demográfico causado por la peste de 1656 cuando, sacando partido de su posición numérica, los vasallos podrán negociar más libremente la definición de las tierras y las condiciones fiscales de su explotación.

\section{CONCLUSIONES}

Los diferentes tipos de inversión económica realizados en el reino de Nápoles no se excluyen de ninguna manera entre sí, al igual que aquellas categorías sociales capaces de extraer excedentes financieros de sus ingresos. El periodo correspondiente al reinado de Felipe II constituye un momento de inflexión en la cronológica relativa a las disponibilidades de colocación del capital, la oferta y las elecciones operadas por los inversores, la demanda. En efecto, es a partir de la segunda mitad del siglo XVI cuando la voluntad integradora de la monarquía española comience a hacerse notar de una forma concreta en el reino de Nápoles. A partir del reinado de Felipe II, los inversores pueden elegir entre el señorío territorial o la adquisición bajo forma feudal de todo tipo de jurisdicciones, rentas del estado o la práctica del comercio.

La nobleza titulada y los barones invierten masivamente el producto de la explotación de sus tierras señoriales, de sus derechos señoriales y de sus jurisdicciones en la compra de rentas del Estado. La monetarización de los excedentes agrícolas o de los derechos señoriales pagados en especie se efectúa mediante su comercialización en el interior del reino, actividad que barones y nobles favorecen y explotan al máximo a través de la construcción y conservación de caminos y puentes y del mantenimiento de relaciones fluidas con negociantes de estatura superior. La participación de los vasallos en tales transacciones resultaba considerablemente menor pues era difícil que sobrepasasen el estadio del autoconsumo.

Es por lo tanto en su calidad de acreedores de la monarquía que los señores muestran indefectiblemente su apoyo a la corona en caso de rebelión de los vasallos, como se puede constatar a partir del estallido revolucionario de 16471648 , cuando fueron los nobles y los barones los que restablecieron el orden en el ámbito provincial. Roberto Mantelli ha demostrado que esta opción financiera por parte, al menos, de los nobles titulados es precoz, incluso anterior a 1556 , y que no es el resultado o la prueba, del proceso de «refeudalización» del siglo XVII descrito por Rosario Villari. Michèle Benaiteau muestra, por su parte, que esta opción es duradera : en el siglo XVIII, la fortuna de los Tocco está constituida en sus tres cuartas partes por renta feudal y en una cuarta parte por títulos sobre la deuda pública, fiscali, arrendamenti, gabelle, de los que una gran parte, como los feudos, se mantenía bloqueada mediante fideicomisos.

Los «genoveses», sinónimo prácticamente aceptado de «hombres de negocio", invierten tanto en el comercio como en las rentas o en los feudos. Sus in-

Hispania, LXİ/2, núm. 208 (2001) 521-538 
versiones se caracterizan por una mayor fluidez en las operaciones, compras y reventas, sin que esto vaya en detrimento de la estabilidad de su asentamiento en el reino. Son mayoritarios en las operaciones propiamente financieras, arriendos y préstamos a la monarquía. Su papel de intermediarios dinamiza los mercados: primero en el comercio internacional y, tras la atribución de las tratas de cereales, logran reconvertir con habilidad sus redes mercantiles para actuar en el comercio interior y en el aprovisionamiento de la capital. En su calidad de arrendatarios, los genoveses subarriendan mediante un proceso de división de los arriendos que se reparten entre hombres de negocio de menor envergadura. Como prestamistas, actúan, en parte, en nombre de otras personas cuya participación queda en el anonimato, o asociándose con otros. Grandes y fervientes compradores de títulos de renta, proceden a su venta tras adaptar su oferta a las disponibilidades de los pequeños ahorradores. Sensibles como todo el mundo al prestigio del feudo y del título, no dudan, sin embargo, en solicitar la autorización para una reventa de las tierras cuando no están satisfechos de su rendimiento. Los genoveses actúan igualmente como intendentes para gestionar los «estados territoriales» de ciertos nobles titulados. Mercaderes, feudatarios o financieros, pueden igualmente hacerse oficiales, generalmente perceptores, con objeto de controlar más de cerca la recaudación de los impuestos que tienen concedida en arriendo.

En su calidad de tercera categoría social que en la segunda mitad del siglo XVI disponía de excedentes financieros, aunque a un nivel claramente inferior al resto, los oficiales capaces de ahorrar - no olvidemos que no todos eran ricos, más bien lo contrario- compran tantos títulos de renta como pueden, conforme salen a la venta y de acuerdo con sus disponibilidades. Frente a lo que hacen los nobles que invierten el producto de sus señoríos en títulos de deuda, lo que supone que no invierten absolutamente nada en una eventual mejora del cultivo de sus tierras, los oficiales compran primero títulos de deuda que utilizarán en el momento adecuado para comprar un señorío, acceder al rango de la nobleza territorial y, ¿por qué no? comprar un título si tienen los medios para conseguirlo. Su participación en las actividades comerciales es bastante difícil de observar al estarles oficialmente prohibidas dichas prácticas. Sin embargo, aflora en numerosos documentos, en particular respecto al comercio de granos al obtener antes que nadie las informaciones concernientes a las diversas medidas proteccionistas de la monarquía. No hay duda de que, también en este caso, el recurso a testaferros es sistemático.

Los diferentes tipos de inversión económica en el reino de Nápoles bajo el reinado de Felipe II ponen de manifiesto la naturaleza tradicional de las actividades desarrolladas, enmarcadas dentro de un tipo de proteccionismo altamente estratégico. Sea cual sea la clase social de la que provienen los fondos invertidos, la posesión de tierras se mantiene como la primera ambición a lo largo del periodo y la adquisición de rentas del Estado representa la inversión más generalizada. Los excedentes financieros permanecen, por lo tanto, en todos los 
casos, inmovilizados en operaciones a muy largo plazo cuyos rendimientos dependen directamente de la productividad que logren alcanzar los campesinos. El trabajo de estos últimos aparece como la única fuente de ganancias, ya sea directamente, a través de la renta señorial o indirectamente a través de la extracción impositiva, al ser ellos los únicos en pagar impuestos. El comercio internacional parece desaparecer a lo largo del siglo XVI en beneficio de los intercambios reglamentados con los otros territorios de la monarquía española. La industria calabresa de la seda, muy fiscalizada durante el siglo XVII, queda eclipsada por la producción siciliana. La industria lanera mantiene, por su parte, mercados básicamente nacionales. A pesar de todo, la economía napolitana siguió siendo floreciente. El reino de Nápoles era una nación rica. Así lo atestiguan los amplios beneficios obtenidos por la monarquía española y por los inversores privados. 